DOI: https://doi.org/10.47405/mjssh.v7i1.1220

\begin{tabular}{|c|c|}
\hline$x=1+2$ & Malaysian Journal of Social Sciences and Humanities (MJSSH) \\
\hline Malaysian Journal of & Volume 7, Issue 1, January 2022 \\
\hline (MJ-ssH) & e-ISSN : 2504-8562 \\
\hline & $\begin{array}{l}\text { Journal home page: } \\
\text { www.msocialsciences.com }\end{array}$ \\
\hline
\end{tabular}

\title{
Teaching Mathematics Based on Graphic Management in Problem Solving Topics
}

\author{
Dharshini Gunasegar¹, Siti Mistima Maat ${ }^{1}$ \\ 1Fakulti Pendidikan, Universiti Kebangsaan Malaysia (UKM), Malaysia \\ Correspondence: Dharshini Gunasegar (dharshinigunasegar@gmail.com)
}

\begin{abstract}
Problem solving is a very important skill in mathematics that students need to master. These skills require logical thinking, deep understanding, mastery of concepts and making connections with existing knowledge. This study aimed to determine the effectiveness of graphic management -based mathematics teaching in problem-solving topics. This study uses a qualitative research approach with a case study design involving one study participant. Participants of the study were randomly selected among year 3 students with a moderate level of Mathematics proficiency. To collect data, graphic management of "Four Corners and A Diamond" and semi -structured interview sessions were conducted. Data collection from graphics management was analyzed descriptively and these interviews were analyzed inductively to obtain specific themes based on the transcripts. Findings of the study show that with this graphic management, students can organize information from questions in the form of appropriate graphics and facilitate their understanding. The implication of this study is that students can solve mathematical problems through the arrangement of information correctly based on the graphic management of "Four Corners and A Diamond". This study can also encourage teachers to use graphic management in helping students to solve non-routine mathematics problems more conceptually.
\end{abstract}

Keywords: mathematical problem solving, graphic management, four corners and a diamond, pupils

\section{Introduction}

Critical, systematic and logical thinking skills are required to know about every situation that occurs in the natural environment. These skills can be developed through learning mathematics (Fasni et al., 2017). In Malaysia, mathematics learning at the primary school level can be divided into four main areas, namely Number, Measurement, Shape and Space and Statistics. Each topic is arranged hierarchically from the most basic to the abstract (Ministry of Education, 2014). Topics in mathematics learning include four categories that should be studied namely facts, skills, concepts and principles. Problem solving skills are very important skills and should be mastered by students. For example, in Japan, a guideline is provided that emphasizes the construction of teaching methods based on existing knowledge and various problem -solving methods learned by students (Asami-Johansson et al., 2020). Yeh et al. (2019), also noted authorities in the education system often emphasize students 'competence in computational and problem -solving skills. 


\section{Research Background}

These problem -solving skills refer to the student's ability to read, understand and identify the main issues of the problem. The ability to solve problems is very important and must be mastered by the student (Fasni et al., 2017). Pupils need a systematic and simple method to help them in solving a given problem by analyzing the problem to organize information logically and practically. To solve math problems, especially sentence problems students must understand the problem first before they can solve problems involving reading skills (Sian et al., 2016).

The problem -solving process is simplified by solving the information in question. The use of graphic management is a way of teaching problem solving skills more effectively. Zollman (2020), states students who use graphic compilers to organize ideas, improve their understanding and strategies to then organize, analyze, and organize knowledge. With graphic management students are able to understand and interpret a given problem more systematically based on their creativity. Drawing pictures, mind maps, making representations and pattern identification are among the important components in this graphic management.

\section{Problem Statement}

Most students often see these problem -solving questions as a difficult process to do. Among the factors are that students do not understand the intent of the question, cannot relate the question to the concepts and cannot think logically. Problems in understanding problems mathematically consist of the representation or transformation of information and the use of mathematical skills to obtain answers (Yusof \& Langkan, 2016). Sari et al. (2017), also discusses students' ability in solving mathematical problems is still low. When they solve verse problems, it is difficult for students to understand the intent of the question and what needs to be done (Shin \& Bryant, 2015).

Each topic in mathematics contains two main sections. The first is content that only involves the calculation of numbers or mathematical sentences while the second is focusing on problem solving. Shanmugam et al. (2021), also discusses that mathematical problems can be presented in the form of calculations or as sentence problems and each poses its own challenges for students. Most students who can solve questions in the form of mathematical sentences correctly cannot solve sentence problems. Factors such as language proficiency and poor understanding of question requirements make it difficult for students to understand mathematical problem-solving questions.

Videnovic (2017), also stated that students will have difficulty reading and understanding mathematical problems in a language in which they have limited skills. Factors of poor understanding of the requirements of problem -solving questions occur because they do not break down and organize information in an effective way. The organization of information in problem -solving questions plays an important role as it leads to the logical way of thinking of students. In fact, students often organize information in an unstructured way that confuses them because it does not have a direction to solve the question.

\section{Research Purpose}

This study aimed to explore the effectiveness of graphic management -based mathematics teaching in problem -solving topics.

\section{Research Questions}

This study aims to understand more about the use of graphics management in the topic of mathematical problem solving and its effectiveness. 
i. How does the use of graphic management help students in understanding the topic of mathematical problem solving?

ii. What improvements can be made to the graphics management used to solve mathematical problems?

\section{Methodology}

This study uses a qualitative research approach with a case study design. This case study involved a selected study participant among Year 3 students with a moderate level of Mathematics proficiency. Ryan (2013), states individual interviews are an effective method of gaining insights into an individual's perceptions, understandings and experiences of a given phenomenon and can contribute to in -depth data collection. The study participants were given the pseudonym Bella. Participants of this study were evaluated through two methods, namely problem -solving worksheet analysis using graphic management Four Corners and A Diamond and semi -structured interviews. Four Corners and A Diamond is a method that gives students space to solve a given question by starting from any desired section. This method is different from the traditional sequential method or procedure shown in the Polya Model (Zollman, 2011).

Figure 1. Four Corners and A Diamond Graphic Management (Zollman, 2011)

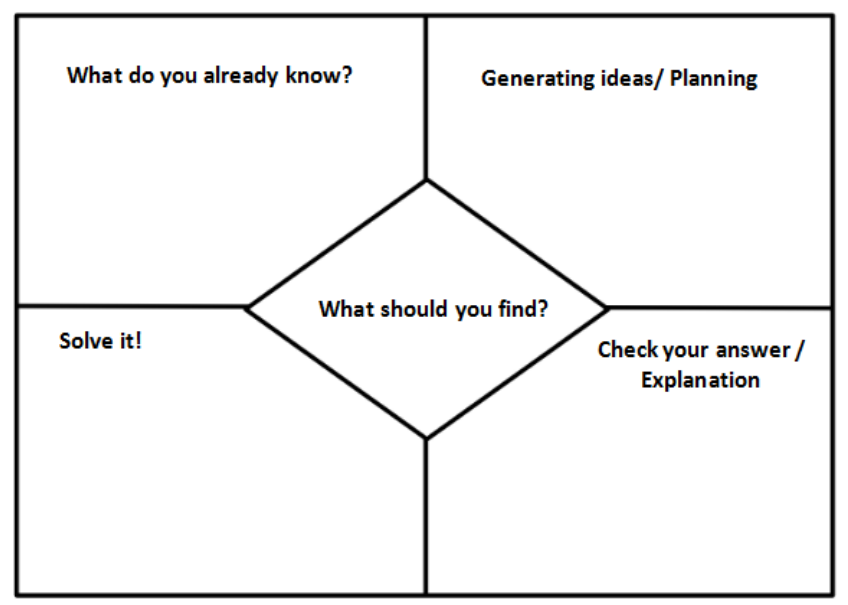

Next, the semi -structured interview was constructed based on the interview protocol framework which consists of four phases as shown in Figure 2 (Castillo-Montoya 2016).

Figure 2. Interview Protocol Framework (Castillo-Montoya 2016)

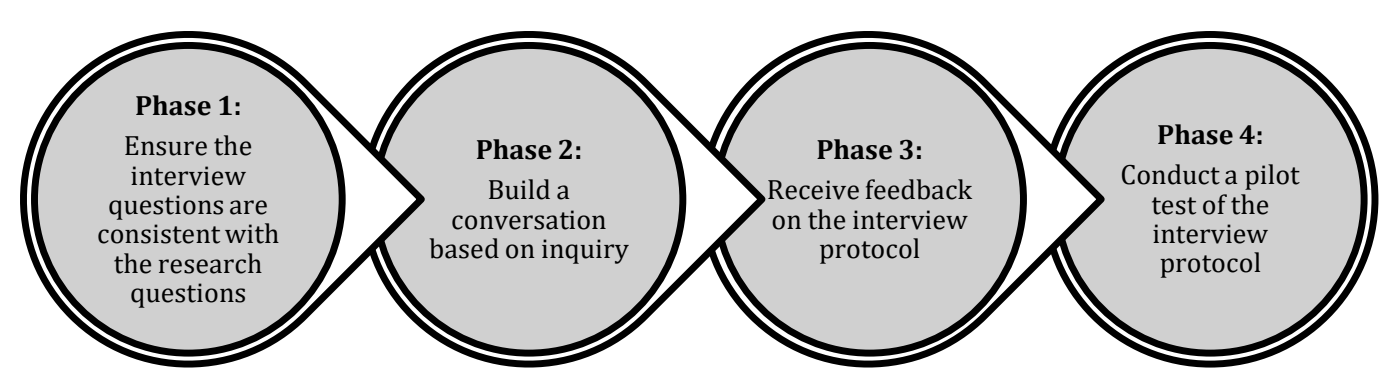


Permission from the management of the study site was obtained first and the researcher began the implementation of the interview protocol with phase 1 . After that, the study participants were also explained about the interview sessions conducted. However, in the implementation of the interview protocol the researcher conducted up to phase 3 only due to time constraints. Castillo-Montoya (2016), in her study also discussed that some researchers may not have the time, money or access to participants to undergo the fourth phase. In that case, phase 3 which is feedback becomes more important to perfect the interview protocol.

In the first phase, the interview questions were constructed in line with the two research questions stated. It helps to obtain relevant data where the answers of the study respondents are within the specified topic range. In this phase, the interview protocol matrix was used as shown in the following table.

Table 1: Interview Protocol Matrix

\begin{tabular}{|c|c|c|}
\hline \multirow{2}{*}{ Interview Questions } & \multicolumn{2}{|c|}{ Research Questions } \\
\hline & Research Questions 1 & Research Questions 2 \\
\hline \multicolumn{3}{|l|}{ Problem solving 1} \\
\hline 1 & I & \\
\hline 2 & l & \\
\hline 3 & I & \\
\hline 4 & I & \\
\hline 5 & & I \\
\hline \multicolumn{3}{|l|}{ Problem solving 2} \\
\hline 1 & l & \\
\hline 2 & l & \\
\hline 3 & l & \\
\hline 4 & l & \\
\hline 5 & & I \\
\hline \multicolumn{3}{|l|}{ Problem solving 3} \\
\hline 1 & l & \\
\hline 2 & l & \\
\hline 3 & l & \\
\hline 4 & I & \\
\hline 5 & & l \\
\hline
\end{tabular}

The second phase is the construction of conversations based on inquiry. The researcher ensures that a variety of questions can be constructed and it needs to create a more friendly and social conversation as well as inquiry -based. The questions asked also have continuity with each other so that the researcher can explore further about the feelings and ways of thinking of the study participants. Each constructed question is concise, clear and easily understood so that it does not affect the flow of the conversation. Finally, based on phase 3 these interview questions were reviewed by a teacher who has more than 10 years of experience in teaching mathematics subjects. This protocol was conducted to increase the reliability of the interview questions that had been constructed. A checklist was distributed to them as follows. 
DOI: https://doi.org/10.47405/mjssh.v7i1.1220

Table 2. Checklist of Interview Protocol Aspects

\begin{tabular}{l} 
Aspects of Interview Protocol \\
\hline An introduction that starts like a normal conversation \\
The questions asked helped to find out the way of thinking of the study \\
participants \\
The questions are reflective in nature and provide an opportunity for \\
study participants to give opinions \\
Each question is constructed based on the research question \\
The closure of the interview showed appreciation to the study \\
participants \\
Only one question is asked at a time. \\
Most of the questions stimulated study participants to express feelings \\
as well as experiences \\
Constructed questions create a good flow of conversation.
\end{tabular}

\section{Data Collection}

To collect data, Four Corners and A Diamond was used for participants to answer problem-solving questions provided and a semi -structured interview session was also conducted. The most common data collection methods used in qualitative research are individual or group interviews (including focus groups), observations, and document reviews (Sargeant, 2012).

Study participants had to answer 3 mathematical problem solving questions using graphic management Four Corners and A Diamond. All three questions are routine problem-solving questions and consist of easy, medium and difficult difficulty levels. These questions are multiplication topic problem-solving questions that consist of direct and indirect statements according to the difficulty level of the question. With this graphic management, study participants read the question and understand the requirements of the question as well as break down the information into specific parts of the graphic management. Ghanizadeh et al. (2020), states that graphic management comes in many types and has been extensively researched for its effectiveness in improving learning outcomes for various students. While completing each of the questions study participants will be interviewed. It was a semi -structured interview. Thus, it is possible to know what the participants think based on the construction of their knowledge while using graphic management. It also helps to obtain information about the feelings of the study participants about the use of graphics management in solving mathematical problems. The questions provided are as follows:

i. Question 1 (Difficulty Level - Easy): Multiplication problem solving involves whole numbers (Direct statement and requires 1 step solution)

SK Bandar Intan has 15 groups for the Lecture Competition. Each group consisted of 24 students. Calculate the number of participants for this competition?

ii. Question 2 (Difficulty Level - Medium): Multiplication problem solving involves time and time (Indirect statements and requires 1 step solution)

The price of a packet of nasi lemak in the school canteen is RM 3.50. What is the amount of money which must be paid by Azmi and 10 of his friends. 
DOI: https://doi.org/10.47405/mjssh.v7i1.1220

iii. Question 3 (Difficulty Level - Difficult): Multiplication problem solving involves measurement (Indirect statement and requires 2 steps solution)

The total distance exercised by Mr.Zahari in a day is $17 \mathrm{~km}$. He exercises 3 times a week. What is the total distance he exercise in March?

\section{Research Findings}

\section{Graphic management Four Corners and A Diamond}

Study participants were given a sheet with 3 problem -solving questions and graphic management Four Corners and A Diamond. Study participants were given a clear description of each aspect of the graphic management. The use of this graphical management showed an increase in study participants in mathematical knowledge, mathematical strategies and mathematical explanations. After being given an explanation, the study participants used five parts of the solution based on the given graphic management and the parts are as follows:

\section{What do you need to find?}

Bella was able to read and understand all three of the problem-solving questions given and was able to record the intent of the questions correctly. For example in question 1, Bella has identified what to look for i.e. the number of participants in the competition and writes it in the diamond section in a given graphic management. Similarly with the other two questions, Bella was able to identify the intent of the question correctly.

Figure 3: Participants understand the requirements of question 1

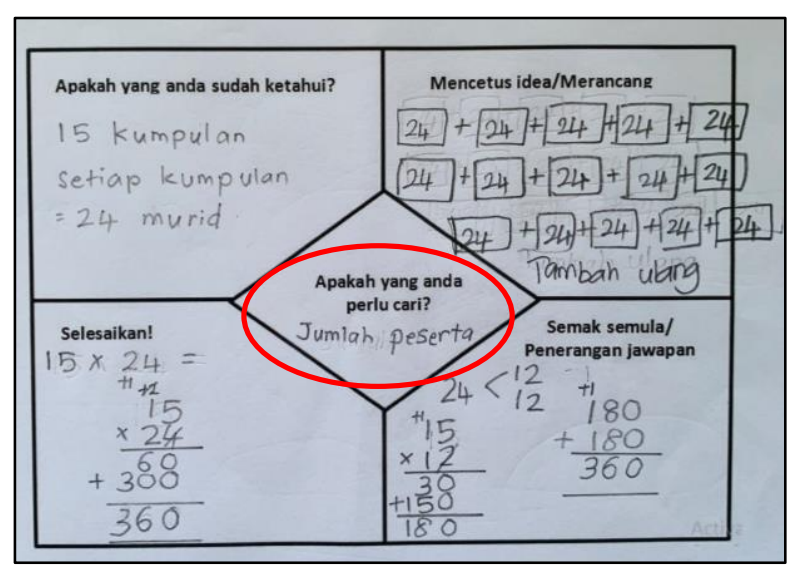

\section{What do you already know?}

In this section, Bella is able to identify important information and understand the relationship between the information. For example, in question 2 given, Bella has written the price of a package which is RM3.50. Bella can understand and know that the number of people who buy nasi lemak is 11 people, including Azmi, instead of writing the number on the question alone, which is 10 friends. 
DOI: https://doi.org/10.47405/mjssh.v7i1.1220

Figure 4: Study participants break down information and write in the "what you already know" section

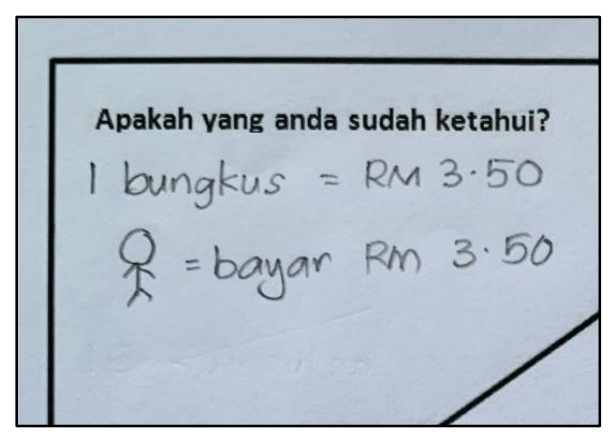

\section{Brainstorm/ Planning}

Bella had drawn pictures as a strategy for problem solving and thus it was found that the study participants had understood the given questions more logically. For question 2, Bella has drawn 11 pictures of people. Found, Bella showed the ability to use the knowledge of strategy that is able to determine the operations and numbers involved in the calculation based on the pictures that have been drawn by her. Indicators of strategy knowledge include identifying all important elements of a problem and demonstrating a complete understanding of the relationships between the elements, reflecting the use of appropriate and systematic strategies to solve the problem (Sutini, 2019). In determining the operations to be involved Bella has identified repetitive addition that is equivalent to multiplication. While in question 3, Bella understands that March is one of the months and knows how to change the word March in question to 4 weeks. Some problem -solving strategies that can be used in solving mathematical problems are finding patterns, drawing pictures (visual representation), calculate all possibilities, manage data, and logical reasoning (Aadzaar \& Widjajanti, 2019). Bella has drawn a picture of 3 boxes and labeled each one as $17 \mathrm{~km}$ to represent 3 times a week. Next the same method was used by Bella to plan a strategy for 1 month i.e. 4 weeks. Bella has written the month of March equal to 4 weeks and drawn 4 boxes to represent the value that will be found in the first step.

Figure 5: Participants plan a strategy by representing information in the form of drawings

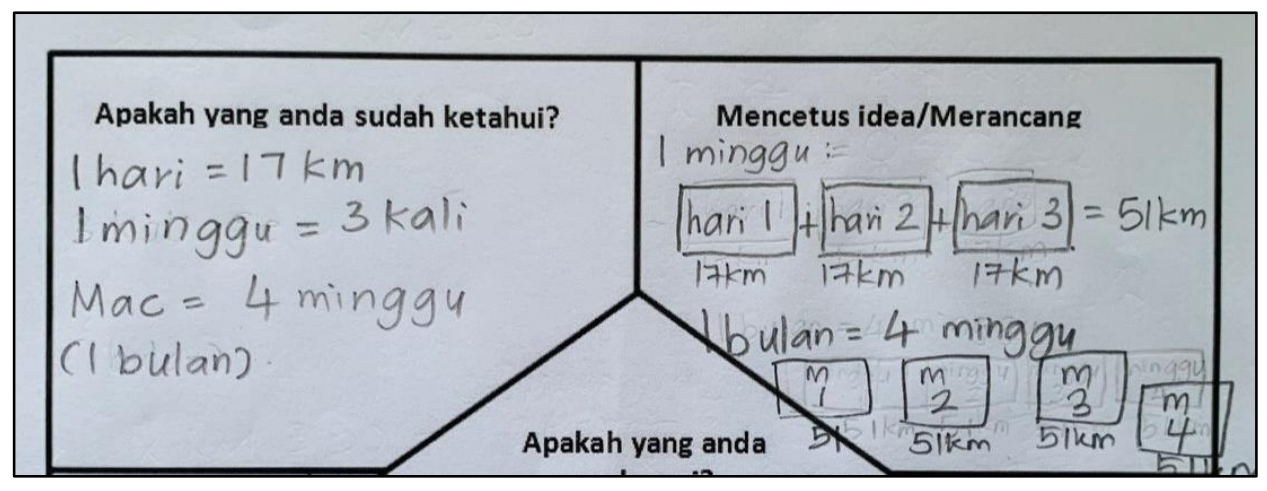

\section{Solve it!}

The next part is problem solving. Bella solves the question based on the operation that has been identified. He has done the calculations correctly for all three questions where the mathematical sentences have been transferred in the usual form. For example, in question 1 he has multiplied 15 by 24 to get the total number of students who have participated in the competition. Similarly with questions 2 and 3 he has calculated the answers in the usual form. 
Figure 6: Solutions in the usual form for all three questions

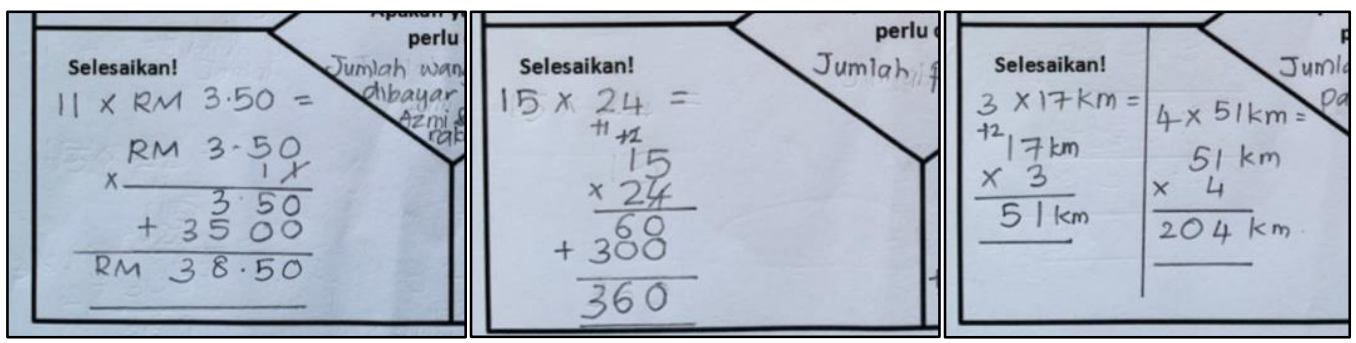

\section{Check it/ Further explanations on your solutions}

Bella has checked to make sure the answers she got are correct. For each question he used a different method and got the same value. For question 1, she has divided 24 by two and got 12 . Next, she has multiplied by multiplying 15 by 12 twice and got the same answer which is 360 . The diagram below shows the step of reviewing the answer that Bella has implemented.

\section{Semi-structured interviews}

A semi-structured interview was conducted while Bella answered all three questions. Jamshed (2014) stated, semi -structured interviews are more in -depth where respondents have to answer open -ended questions and it is also widely used in qualitative research. The interviews that have been conducted help in getting Bella's way of thinking in understanding a question based on the construction of her knowledge. These interviews were analyzed inductively to elicit specific themes based on the transcripts. Inductive analysis is a qualitative analysis technique that involves reading raw data and understanding it by acquiring specific categories and themes (Yukhymenko et al., 2014). A total of 4 codes were determined based on the themes found as shown in the following table:

Table 3: Themes and Code Determination

\begin{tabular}{cc}
\hline Theme & Code \\
\hline Understand the question & $\mathrm{A}$ \\
Strategies used & $\mathrm{B}$ \\
How to think logically & $\mathrm{C}$ \\
Opinions/feelings on graphic management & $\mathrm{D}$ \\
\hline
\end{tabular}

During Bella's interview there was a variety of information identified. Each piece of information is categorized according to themes such as understanding the question, strategies used, way of thinking and opinions or feelings towards graphic management. Each of these themes is coded A, B, C, and D respectively. Code determinations were made for all three interviews conducted while Bella was answering questions. If Bella can tell what she understands from a given situation then it shows she understands the question and is given code A. When Bella explains the strategy she uses in any part of graphics management will be given code $\mathrm{B}$. Code $\mathrm{C}$ is given for the theme of thinking logically where Bella's answer shows the way she thinks to solve the three questions. Finally, code D is given for Bella's answer which shows her opinion or feelings while using the graphic management. The following is a table showing the themes created with examples of information obtained from semi structured interviews. 
Table 4. Theme description and code determination

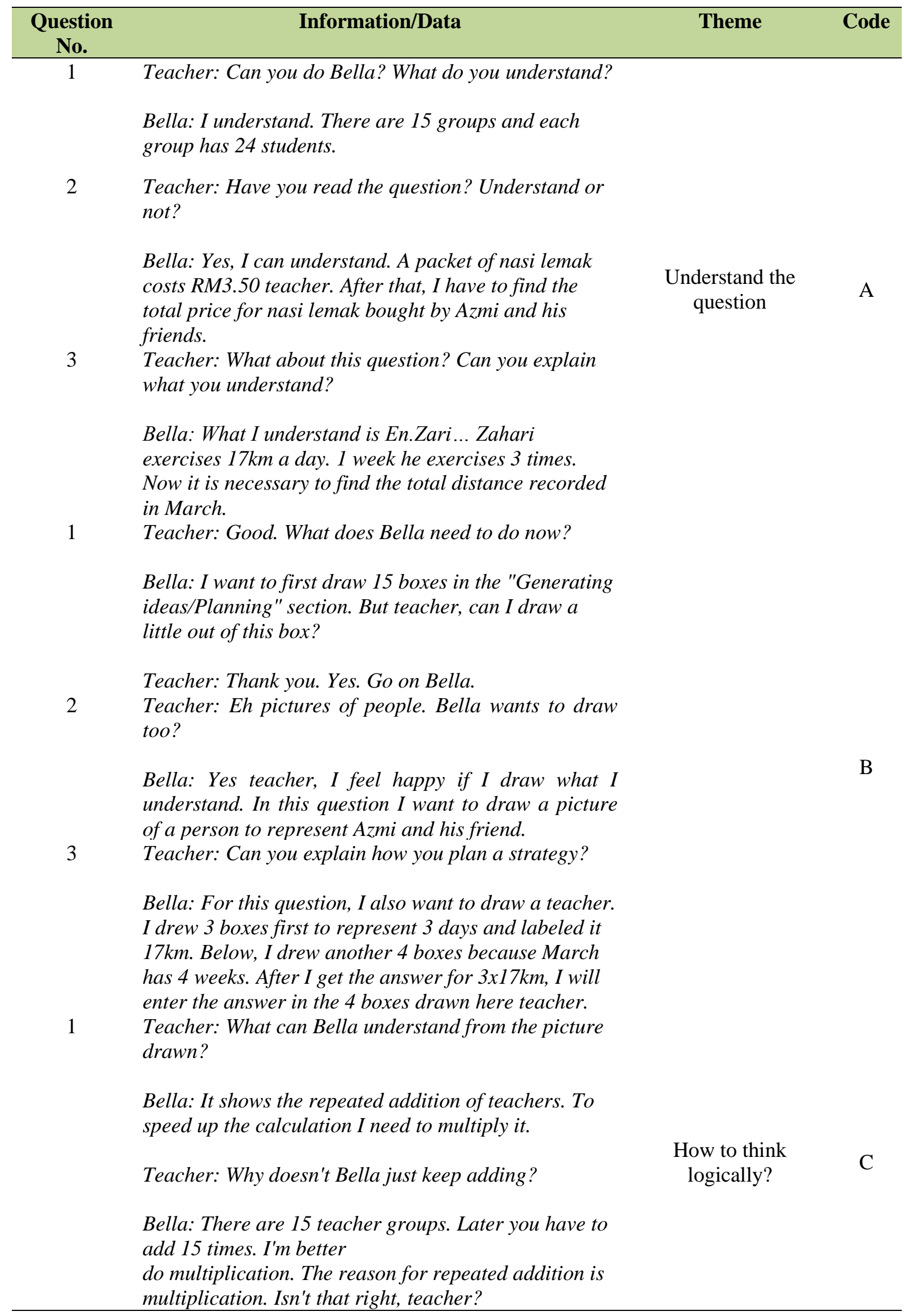


Teacher: Yes, that's right. Proceed.

Bella: The reason in the question is mentioned aah... Azmi and 10 of his friends. That means 10 plus 1 so 11 teachers because Azmi also bought nasi lemak. That's why I multiply by 11.

3 Teacher: What the teacher can see is Bella drawing some boxes. Can you explain?

Bella: Okay sir. He exercises $17 \mathrm{~km}$ a day and in a 3 day week he exercises. That means all three days he worked out $17 \mathrm{~km}$.

Teacher: How fast are you looking for an answer? Bella: Yes teacher, because I like this way. His name is "Four Corners and one... A Diamond" right? I love. If there are many more beautiful colors. Previously I only searched for keywords. Now in this there are many parts. I understand better.

Bella: I can also check my answers in this section.

Opinions/Feelings on Graphic Management
$\mathrm{D}$

Bella: Before, I only made fibers. Finally I was confused by the steps I wrote. This way there are parts and there are names of their own. The one I like the most is the idea trigger part because I can draw what I read in the question.

The results of this study show that Bella can solve these questions using graphic management more easily. The graphic management of "Four Corners and A Diamond" helps him to break down information in an orderly and clear manner. Each part of this graphic management allows Bella to think of ways to solve it by understanding the given questions in a more practical and logical way. The codes set for the created theme show graphic management helps Bella in terms of understanding the intent of the question, planning strategies, revising and her way of thinking to solve problems in a more orderly manner.

\section{i. Understand the question}

This theme is created for each of Bella's statements indicating she has understood the question given. It also showed he had read the question carefully and understood the meaning of the situation. He was able to describe in his own words what he had read. The first part of this graphic management helps him to read and understand the questions. Having understood the question he analyzed only the important information to be written in the first part. He was able to understand all three questions consisting of different levels of difficulty with component guidance in the management of such graphics.

\section{ii. Strategies used}

Code B is determined for the strategy theme used. This theme was created based on the description given by Bella of the strategies she used. By drawing a picture in the "planning/generating ideas" section, he can convert the information from the question into a diagram. It helps him to see such abstract situations into semi-concrete situations. For example in question 1, Bella has drawn 15 boxes to represent 15 groups and labeled each one with the number 24 as the number of pupils. The idea 
generation part of this graphic management helps Bella to think of an appropriate strategy for representing what she already knows.

Figure 8: Triggering an idea with a picture drawing

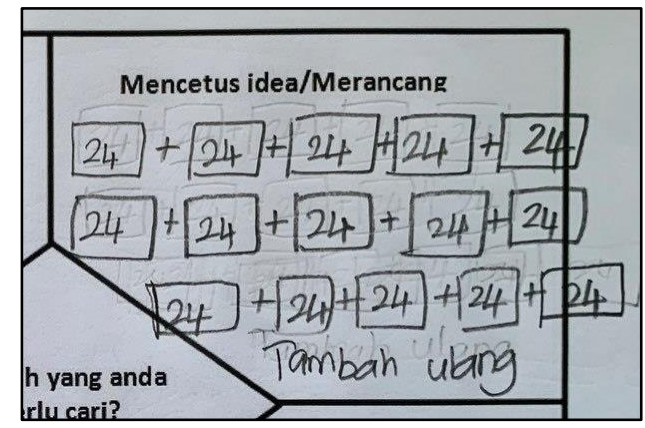

\section{iii. How to think logically}

This conversation showed that study participants were able to represent a given situation by drawing a picture. For example, after he draws a picture he can explain that it involves repeated addition where he has to multiply it. Since this question has a large number then, he chooses to multiply instead of adding the number 24 by 15 times. This statement shows the way Bella thinks to justify what she has drawn. Next, Bella was also able to review the answers obtained. For question 1, he has multiplied 15 by 12 twice and the method used shows his level of logical thinking. He knows that the sum of 12 and 12 is 24 so he uses this method to check the answer.

\section{iv. Opinions/feelings on graphic management}

The fourth theme that can be identified is opinions or feelings towards graphic management. The theme is coded D and it refers to each statement related to Bella's feelings and opinions in using graphic management to solve all three questions given. He has stated graphic management has many parts that help him to think more focused. Previously, he only read questions and searched for keywords such as amount and balance to identify the operations involved. With this graphic management, he states he better understands the question and solves it correctly. According to Bella, graphic management is a very clear and easy method to use in problem solving questions because there is a clear guide or direction.

During the interview, Bella also stated that she really liked the idea -sparking part because she was able to represent what had been read in the question in the form of pictures. He thinks it strengthens his understanding and serves as a guide for the next step. He also expressed feeling very confident when getting the same answer in the review section. Gurat (2018), stated that if the answer matched their examination, they were confident that the answer was correct. Throughout the use of this graphic management, he felt very confident and enthusiastic he said.

\section{Discussion}

The study conducted has helped to collect data on the implications of graphic management for students and improvements that can be made to the graphic management.

\section{The effectiveness of graphic management on problem solving topics}

Mathematical problem solving requires logical thinking and solid mathematical knowledge. It brings diversity in performing basic mathematical operations and prepares students to apply mathematical skills in everyday situations outside the classroom (Pongsakdi et al., 2020). Graphic 
management -based mathematics teaching can help students to solve sentence problems with clear guidance. This "Four Corners and A Diamond" has many implications for students where they use it more effectively. Based on the identified themes this graphic management helps students in understanding the question, triggering ideas for strategic planning, stimulating logical thinking and creating a positive perception of it. It also ensures students to master problem -solving skills comprehensively.

Pupils are able to solve the given questions in a more simple and orderly way through this graphic management. It consists of specific parts for each process that needs to be implemented. With that, the student understands and solves it more easily with the correct solution steps. The use of these graphics stimulates students to plan strategies with clearer data representations and solutions for reference. At the level of information organization, mathematical abstraction and graphical analysis lead to the development of a plan for its solution (Szabo et al., 2020). It also encourages students to review each error that occurs separately. If there are any mistakes they do not have to repeat from a step or process from the beginning. They only need to correct on certain parts only.

Furthermore, the results of the study show that this graphic management can stimulate students' logical thinking. It allows students to use their mathematical knowledge to explain solutions that have been implemented. For example, after reading the question with graphic management guidance they will try to understand the question to be written on the section provided. They need to use mathematical knowledge to plan solution strategies for what has been understood. According to (Sutini 2019), indicators of mathematical knowledge include: demonstrating a complete understanding of the concepts and principles of mathematical problems, using appropriate mathematical terms and symbols, and using complete and accurate algorithms. It in turn allows students to begin to draw the information that has been obtained and this shows the processing of the information logically. Pupils are also able to construct correct mathematical sentences for the questions read by using the correct mathematical symbols. This graphic management encourages students 'interest in solving any given problem because they have clear guidelines.

The guide is able to give confidence to students to solve verse problem questions correctly. Instead of just reading and looking for key words in a question, students can be stimulated to think logically and understand the intent of the question conceptually. Most teachers in the United States define a problem as a single operation (e.g." "Today, we're going to learn a problem solving for the topic of division") and associate keywords (e.g., "more, amount, balance, share, twice") with a specific operation (e.g., "divide"). Unfortunately, teaching students to solve word problems in this way does not encourage mathematical reasoning and often results in incorrect answers (Powell \& Fuchs 2018). This graphic management is also more comfortable to use because students can choose the parts to be made first instead of performing each step in a specific sequence. The findings of the study also show that students are interested in using every part available in the graphic management. This shows their understanding of the importance of each step taken.

\section{Improvements to graphics management}

Graphic management Four Corners and A Diamond guides students to think logically in solving problem -solving questions. However, it also needs improvement to make it a very comprehensive and effective method. This graphic management should be accompanied by the use of various colors. Color plays an important role in stimulating students to understand something being read more effectively. Colors help in memorizing certain information by increasing an individual's level of attention (Dzulkifli \& Mustafar, 2013). This graphic management only involves black which may be boring for students. Most students especially those who are at a weak and moderate level of mastery will be more interested in the use of various colors. Pupils are also able to remember something taught more firmly when the element of color is applied. For example, each part in the graphic management of Four Corners and A Diamond has different colors and it is able to help students to remember each part by identifying the colors that have been seen in it. 
In addition, any graphic management used should have sufficient space for students to write their solution steps. This graphic management consists of four rectangles and a diamond shape. The arrangement of these forms makes it quite difficult for students to write solution steps. The diamond shape found in the middle between the four rectangles makes the space for writing answers quite narrow. This caused the student to write and delete many times and it took quite a long time to complete it. The arrangement of forms in this graphic management also plays a role in helping students more effectively. The position of the shapes can be modified or replaced with a more suitable shape.

\section{Implications of the Study}

This study can help teachers to improve the practice of mathematics pedagogy, especially in the topic of problem solving. Teachers can learn the importance of the use of graphic management in helping students to solve verse problems. In solving verse problems, students need critical and logical thinking skills. With that, they are able to understand the intent of the question and break down the information given. Graphic management is an appropriate intervention or method used by teachers to guide students in organizing information. Through the teaching of this graphic management-based problemsolving topic, teachers can ensure that students have a clear direction. They can break information down into specific parts. With graphic management, teachers can also identify students' weaknesses in specific areas and can guide them more effectively.

In addition, students are also able to answer problem-solving questions more effectively compared to other traditional methods. This graphic management helps students to solve problems part by part. They are able to identify their mistakes and correct them immediately because the written information is more organized and clear. Graphic management also prevents students from simply identifying specific keywords to select the operations that need to be performed. In fact, it ensures that students are able to gather information and subsequently plan strategies with a stronger and more logical understanding such as drawing diagrams.

\section{Recommendations for Further Studies}

This study can be a reference to other researchers who want to conduct research that is relevant to the issue of this study. Based on the above discussion, the studies to be conducted should focus on the improvement of the graphics management used and the use of appropriate graphics management used according to the level of mastery of the study participants.

The aspect that needs to be improved in this graphic management is the way the shapes are arranged effectively. Researchers need to ensure that the graphic management used has sufficient space so that study participants can write answers comfortably. Graphic management should also have an element of color that is able to attract the interest and attention of study participants as well as encourage a stronger memory. In addition, the researcher can also focus on visual representation further and study how it helps study participants in solving verse problems. Based on the discussion in this study, it was found that the study participants had planned a strategy by drawing pictures and it has helped to understand the collected information more logically. Researchers can also modify the management of this graphic according to the target group according to the results of the study to be seen. This is because, different levels of mastery may give different findings about the effectiveness of the use of graphics management.

\section{Conclusion}

Mathematical problem solving can help students in improving their analytical thinking skills and help them apply those skills in a variety of situations (Mailisman et al., 2020). The use of graphic management in mathematical problem -solving topics helps students to solve questions with the selection of appropriate strategies. Pupils show stronger mastery in understanding questions and 
organizing information into small parts. Graphic management consisting of five main parts serves as a guide for students to understand the questions and solve them without confusion in organizing the information. It also assists students in representing each piece of information in a question logically and conceptually. Drawing a picture is an effective strategy for students to generate ideas by representing the information. Teachers can also identify student mistakes in a more focused manner with the use of this graphic management.

Overall, the results of this study show that graphic management improves students' mastery and understanding of mathematical problem solving. The results show that students have high confidence when solving verse problems with clear guidance found in the graphic management of Four Corners and A Diamond. Teachers should ensure that appropriate strategies such as graphic management can be used to assist students in mastering sentence-based math problem solving skills. With appropriate graphic management, teachers can identify weaknesses and strengths of students' skills in problem solving as well as plan comfortable and familiar methods to facilitate the teaching of problem solving topics (Zollman, 2012).

\section{References}

Aadzaar, R. M. \& Widjajanti, D. B. (2019). Multimedia: An alternative to improve self-regulated learning and mathematical problem-solving skills. Journal of Physics: Conference Series 1320(1). doi:10.1088/1742-6596/1320/1/012086

Asami-Johansson, Y., Attorps, I. \& Winsløw, C. (2020). Comparing mathematics education lessons for primary school teachers: case studies from Japan, Finland and Sweden. International Journal of Mathematical Education in Science and Technology, 51(5), 688-712. doi:10.1080/0020739X.2019.1614688

Castillo-Montoya, M. (2016). Preparing for interview research: The interview protocol refinement framework. Qualitative Report, 21(5), 811-831. doi:10.46743/2160-3715/2016.2337

Dzulkifli, M. A. \& Mustafar, M. F. (2013). The influence of colour on memory performance: a review. The Malaysian journal of medical sciences: MJMS, 20(2), 3-9. Retrieved from http://www.ncbi.nlm.nih.gov/pubmed/23983571\%0Ahttp://www.pubmedcentral.nih.gov/articlere nder.fcgi?artid=PMC3743993

Fasni, N., Turmudi, T. \& Kusnandi, K. (2017). Mathematical Problem Solving Ability of Junior High School Students through Ang's Framework for Mathematical Modelling Instruction. Journal of Physics: Conference Series, 895(1). doi:10.1088/1742-6596/895/1/012082

Ghanizadeh, A., Al-Hoorie, A. H. \& Jahedizadeh, S. (2020). Graphic organizers. Second Language Learning and Teaching, 53-100. doi:10.1007/978-3-030-56711-8_2

Gurat, M. G. (2018). Mathematical problem-solving strategies among student teachers. Journal on Efficiency and Responsibility in Education and Science, 11(3), 53-64. doi:10.7160/eriesj.2018.110302

Jamshed, S. (2014). Qualitative research method-interviewing and observation. Journal of Basic and Clinical Pharmacy, 5(4),87. doi:10.4103/0976-0105.141942

Mailisman, N., Ikhsan, M. \& Hajidin. (2020). Mathematics problem-solving skills of vocational high school students related to the 21st-century education. Journal of Physics: Conference Series, 1460(1). doi:10.1088/1742-6596/1460/1/012014

Pongsakdi, N., Kajamies, A., Veermans, K., Lertola, K., Vauras, M. \& Lehtinen, E. (2020). What makes mathematical word problem solving challenging? Exploring the roles of word problem characteristics, text comprehension, and arithmetic skills. ZDM - Mathematics Education, 52(1),33-44. doi:10.1007/s11858-019-01118-9

Powell, S. R. \& Fuchs, L. S. (2018). Effective Word-Problem Instruction: Using Schemas to Facilitate Mathematical Reasoning. Teaching Exceptional Children, 51(1), 31-42. doi: $10.1177 / 0040059918777250$

Ryan, F. (2013). Interviewing in qualitative research: The one-to-one interview. International Journal of Therapy and Rehabilitation, 16(6). Retrieved from https://doi.org/10.12968/ijtr.2009.16.6.42433

Sargeant, J. (2012). Qualitative Research Part II: Participants, Analysis, and Quality Assurance. Journal of Graduate Medical Education, 4(1), 1-3. doi:10.4300/jgme-d-11-00307.1 
Sari, D. S., Kusnandi, K. \& Suhendra, S. (2017). A Cognitive Analysis of Students' Mathematical Communication Ability on Geometry. Journal of Physics: Conference Series, 895(1). doi:10.1088/1742-6596/895/1/012083

Shanmugam, S. K. S., Veloo, A. \& Md-ali, R. (2021). The Mathematics Performance of Aboriginal Pupils for Computation and Word Problem Items in Using Academic and Community Languages 17(8).

Shin, M. \& Bryant, D. P. (2015). A Synthesis of Mathematical and Cognitive Performances of Students With Mathematics Learning Disabilities. Journal of Learning Disabilities, 48(1), 96-112. doi:10.1177/0022219413508324

Sian, K. J., Shahrill, M., Yusof, N., Ling, G. C. L. \& Roslan, R. (2016). Graphic organizer in action: Solving secondary mathematics word problems. Journal on Mathematics Education, 7(2), 83-90. doi: $10.22342 /$ jme.7.2.3546.83-90

Sutini, S. (2019). Kemampuan Metakognitif dan Komunikasi Matematis dalam Pemecahan Masalah Matematika. Jurnal Review Pembelajaran Matematika, 4(1), 32-47. doi:10.15642/jrpm.2019.4.1.32-47

Szabo, Z. K., Körtesi, P., Guncaga, J., Szabo, D. \& Neag, R. (2020). Examples of problem-solving strategies in mathematics education supporting the sustainability of 21 st-century skills. Sustainability (Switzerland), 12(23),1-28. doi:10.3390/su122310113

Videnovic, M. (2017). Oral vs. written exams: What are we assessing in Mathematics? Imvi - Open Mathematical Education Notes, 7(1). doi:10.7251/OMEN1701001V

Yeh, C. Y. C., Cheng, H. N. H., Chen, Z. H., Liao, C. C. Y. \& Chan, T. W. (2019). Enhancing achievement and interest in mathematics learning through Math-Island. Research and Practice in Technology Enhanced Learning, 14(1). doi:10.1186/s41039-019-0100-9

Yukhymenko, M. a, Brown, S. W., Lawless, K. a, Brodowinska, K. \& Mullin, G. (2014). Thematic Analysis of Teacher Instructional Practices and Student Responses in Middle School Classrooms with Problem-Based Learning Environment. Global Education Review, 1(3), 93-109.

Yusof, J. \& Langkan, J. (2016). Word Problems Involving Fractions: A Case of Year 5 Pupils in Brunei Darussalam. 6th International Conference on Language, Education, and Innovation, 47-53. Retrieved from http://proceedings.icsai.org/6iclei/6iclei-016.pdf

Zollman, A. (2012). Facilitating Student Mathematical Problem Solving: The Mistaken Idea of Linear Thinking.

Zollman, A. (2020). Mathematical Graphic Organizers. Teaching Children Mathematics, 16(4), 222229. doi:10.5951/tcm.16.4.0222 